PREPARED FOR THE U.S. DEPARTMENT OF ENERGY, UNDER CONTRACT DE-AC02-76-CHO-3073

PPPL-3271

PPPL-3271

UC-420, 421

Transport of Recycled Deuterium to the Plasma Core in TFTR

by

C.H. Skinner, M.G. Bell, R.V. Budny, D.L. Jassby, H. Park, A.T. Ramsey, D.P. Stotler, and J.D. Strachan

October 1997
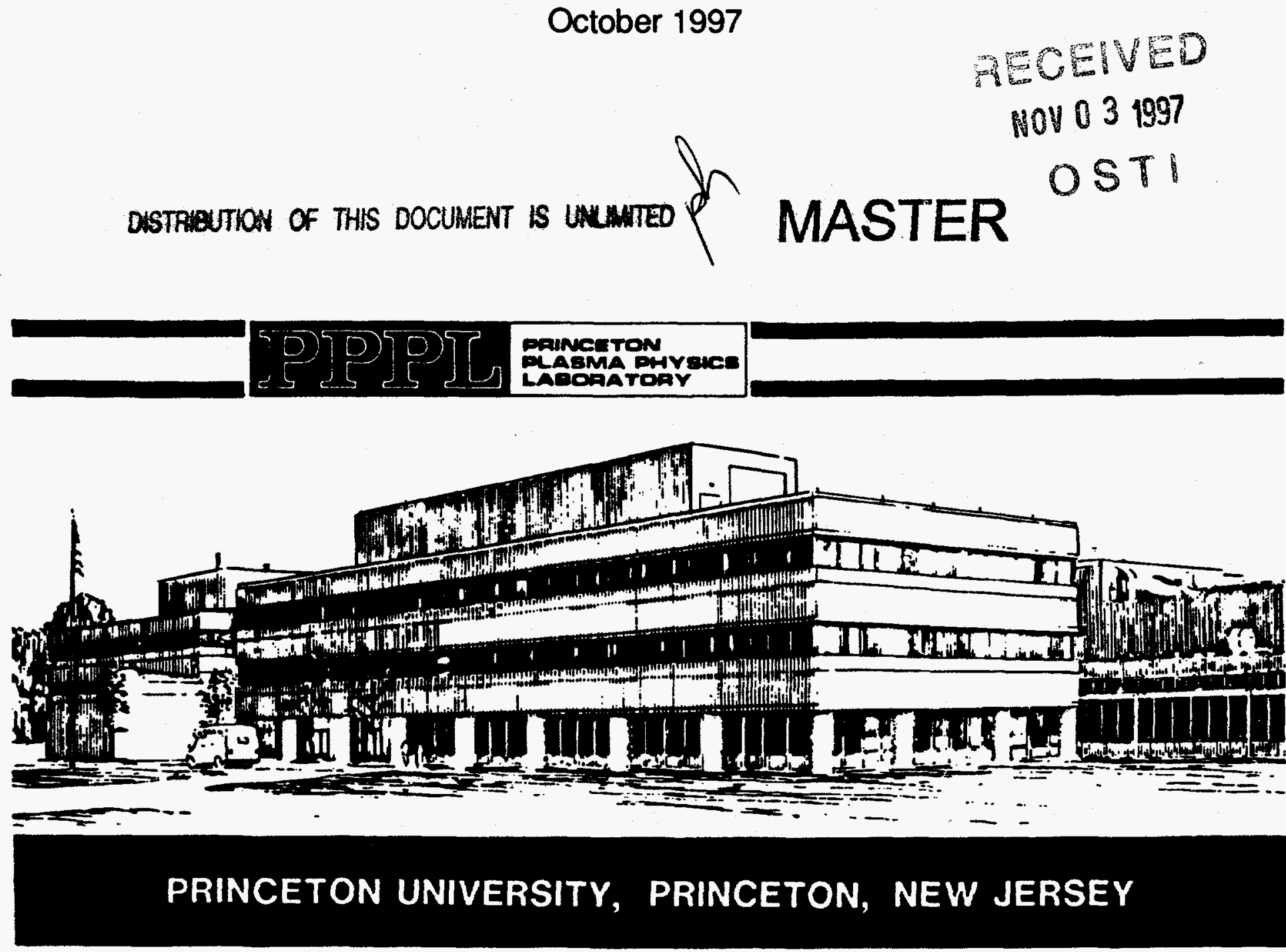


\section{PPPL Reports Disclaimer}

This report was prepared as an account of work sponsored by an agency of the United States Government. Neither the United States Government nor any agency thereof, nor any of their employees, makes any warranty, express or implied, or assumes any legal liability or responsibility for the accuracy, completeness, or usefulness of any information, apparatus, product, or process disclosed, or represents that its use would not infringe privately owned rights. Reference herein to any specific commercial produce, process, or service by trade name, trademark, manufacturer, or otherwise, does not necessarily constitute or imply its endorsement, recommendation, or favoring by the United States Government or any agency thereof. The views and opinions of authors expressed herein do not necessarily state or reflect those of the United States Government or any agency thereof.

\section{Notice}

This report has been reproduced from the best available copy. Available in paper copy and microfiche.

Number of pages in this report: 16

U.S. Department of Energy and Department of Energy Contractors can obtain copies of this report from:

Office of Scientific and Technical Information

P.O. Box 62

Oak Ridge, TN 37831

(615) 576-8401

This report is publicly available from the:

National Technical Information Service

Department of Commerce

5285 Port Royal Road

Springfield, VA 22161

(703) $487-4650$ 


\section{DISCLAIMER}

Portions of this document may be illegible in electronic image products. Images are produced from the best available original document. 


\title{
Transport of recycled deuterium to the plasma core in TFTR.
}

\author{
C H Skinner, M G Bell, R V Budny, D L Jassby, H Park, \\ A T Ramsey, D P Stotler, and J D Strachan \\ Plasma Physics Laboratory, Princeton University \\ P. O. Box 451, Princeton, N. J. 08543
}

\begin{abstract}
We report a study of the fueling of the plasma core by recycling in the Tokamak Fusion Test Reactor (TFTR) [Phys. Plasmas 2, 2176 (1995)]. We have analyzed discharges fueled by deuterium recycled from the limiter and tritium-only neutral beam injection. In these plasmas, the DT neutron rate provides a measure of the deuterium influx into the core plasma. We find a reduced influx with plasmas using lithium pellet conditioning and with plasmas of reduced major (and minor) radius. Modeling with the DEGAS neutrals code shows that the dependence on radius can be related to the penetration of neutrals through the scrape-off layer.
\end{abstract}

PACS numbers: 52.25.Fi, 52.40.Hf, 52.55.Fa,

\section{Introduction.}

Recycling is a major fueling source in tokamaks. The influx of recycled deuterium is traditionally estimated from measurements of the deuterium Balmer-alpha emission which is a measure of the ionization of incoming neutral deuterium at the plasma edge. ${ }^{1}$ However the fueling of the core plasma by recycled deuterium depends additionally on the probability of ionized deuterium being transported to the plasma core. An interesting opportunity to study the transport of recycled deuterium through the scrape-off region to the plasma core occurs in plasmas where the neutral beam injection is solely tritium. On reaching the core, the deuterium undergoes $\mathrm{D}-\mathrm{T}$ reactions with the tritium injected by the beams. As the sole source of deuterium is the limiter, the resulting $14 \mathrm{MeV}$ neutron rate is a measure of the combined effects of deuterium recycled from the limiter and its transport through the scrape-off 
layer and outer plasma regions to the plasma core. In this paper we relate the D-T neutron rate to the relative deuterium density in the core and find that the influx to the core is not simply proportional to the D-alpha emission, but also depends geometry of the plasma edge. A reduced core deuterium density is also evident with lithium wall conditioning.

The Tokamak Fusion Test Reactor, TFTR, operated routinely with deuterium-tritium (D-T) plasmas. Fusion powers up to $10.7 \mathrm{MW}$ were obtained in plasmas heated by high power tritium and deuterium neutral beam injection. ${ }^{2}$ The fusion reactivity and ion stored energy were heavily dependent on the core fueling by the neutral heating beams. ${ }^{3}$ The attenuation of the injected neutral beams is, to first order, dependent on the local electron density, and efficient core fueling required low edge densities. The TFTR plasma boundary is defined by an inner toroidal belt limiter composed of $22 \mathrm{~m}^{2}$ of carbon tiles. The deuterium influx from the limiter was minimized by ohmic conditioning discharges ${ }^{4}$ and in some cases by lithium pellet injection. ${ }^{5}$ However, despite the substantial reductions achieved, recycling from the limiter remained a major fueling source for the plasma (typically, there is no gas feed after the initiation of the discharge). Previous modeling of supershots in TFTR 6 has shown that the local recycling source was larger than the beam fueling source from the half radius to the edge. However, the beam particles deposited in the plasma core dominate the central fueling.

While recycling is a significant factor in core plasma composition, it is more difficult to control than the beam fueling. Deuterium influx limited the range of isotopic mass that could be explored in a study of the isotopic scaling of transport. ${ }^{7,8}$ Deuterium influx may also have played a role in limiting the duration of the high performance phase of a discharge. In some cases, after reaching a maximum, the neutron rate degraded before the end of the neutral beam heating and this has been attributed to a rising influx rate from the limiter. ${ }^{9}$ Operational experience has been that this 'rollover' tends to be more prevalent in plasmas of large $(\mathrm{R}=2.6 \mathrm{~m})$ major radius. Studies of tritium recycling in discharges with deuterium-only neutral beam injection were reported in refs. 10 and 11 . The variation of energy confinement with plasma size in TFTR $L$-mode discharges was reported in ref. 12.

The total Balmer-alpha intensity from hydrogen, deuterium and tritium was measured on TFTR by a photo-diode array. ${ }^{13}$ The relative fraction of $\mathrm{H}, \mathrm{D}$ and $\mathrm{T}$ was also measured at one location by resolving the Balmer-alpha line profile with a Fabry-Perot interferometer. ${ }^{14}$ The hydrogenic influx is dominantly deuterium, with a $10-25 \%$ fraction of hydrogen. The tritium fraction, $T_{\alpha} /\left(H_{\alpha}+D_{\alpha}+T_{\alpha}\right)$ is typically less than $10 \%$, even with tritium-only neutral beam injection. However, in experiments with large tritium gas puffs (excluded in the present study), this fraction increased to greater than 50\%. ${ }^{15}$ Hydrogen (protium) is an intrinsic impurity in the limiter tiles. Currently, analysis codes (TRANSP, ${ }^{16}$ SNAP ${ }^{17}$ ) use a fueling rate through the last closed flux surface that is based on the total Balmer-alpha intensity. Thus it is interesting to examine the correlation of the deuterium density derived from the DT neutron rate with the Balmer-alpha intensity. 


\section{Scaling of neutron rate with plasma parameters.}

The local D-T fusion power density is proportional to $n_{D} n_{T}\left\langle\sigma_{D T} u\right\rangle$ where $n_{D}$ and $n_{T}$ are the deuterium and tritium densities, $\sigma_{D T}$ the fusion cross section, and the average, \langle\rangle , is over the relative velocity, $u$, of deuterium and tritium. Empirically, in plasmas with a balanced mixture of D and $\mathrm{T}$ in the core, the fusion power is found to scale approximately with the square of the stored energy in the plasma. This may be understood in the following way: in the plasma conditions of interest $\left\langle\sigma_{D T} u\right\rangle$ varies approximately with the square of the temperature. If we neglect impurities, assume $n_{D} \approx n_{T}$, and combine the beam-target, beam-beam and thermonuclear reaction pathways with a single 'effective' temperature, $T_{i}$, the fusion power, integrated over volume, varies approximately as:

$$
\begin{aligned}
P_{D T} & \propto \int n_{i}^{2} T_{i}^{2} d V \\
& \propto K\left[\int\left(n_{i} T_{i}+n_{e} T_{e}\right) d V\right]^{2} / V \\
& \propto K W_{t o t}{ }^{2} / V
\end{aligned}
$$

where $\mathrm{V}$ is the plasma volume, $W_{\text {tot }}$ the total stored energy and by definition

$$
K \equiv \frac{\left[\int n_{i}^{2} T_{i}^{2} d V\right] / V}{\left\{\left[\int\left(n_{i} T_{i}+n_{e} T_{e}\right) d V\right] / V\right\}^{2}}
$$

is a dimensionless factor dependent on the ion and electron pressure profile shapes and the ratio of the central ion to electron pressure.

Following the scheme used by Bell et al. ${ }^{18}$ to determine the ratio of the fusion power from similar DT and D-only plasmas, a regression analysis of 243 plasmas, restricted to DT discharges with a tritium NBI power fraction between 0.35 and 0.75 , yields the following relation for the DT neutron rate, $S_{D T}$ :

$$
S_{D T} \cong 1.74 \times 10^{7} W_{t o t}^{1.87} q_{a}^{0.24} V_{p}^{-1}
$$

Here $W_{t o t}$ is the total stored energy derived from magnetic measurements, $q_{a}$ is the edge MHD safety factor and $V_{p}$ is the plasma volume, all measured at the time of maximum stored energy. This scaling will not be valid for discharges with tritium-only NBI. In that situation $S_{D T}$ will depend on the influx of deuterium from the limiter and the transport of deuterium to the reacting core. A measure of the deuterium in the reacting core may be obtained by comparing the D-T fusion power in a discharge with tritium-only NBI to that expected from a discharge with the same stored energy and approximately equal amounts of $\mathrm{D}$ and $\mathrm{T}$ injection. We define the fractional ratio $F_{1}$, 


$$
F_{1}=S_{D T} / 1.74 \times 10^{7} W_{\text {tot }}^{1.87} q_{a}^{0.24} V_{p}^{-1}
$$

where $S_{D T}$ is now the measured DT neutron rate, as a gauge of that influx. Assuming that the plasma pressure profile shapes, the ratio of ion to electron temperature and the impurity content are unaffected by a change to T-only NBI, we can express the fraction of deuterium in the reacting region of the plasma in terms of $F_{1}$. For $n_{D}<n_{T}$, within the approximation of a single value of $\left\langle\sigma_{D T} u\right\rangle$, the ratio of the central densities is:

$$
\frac{n_{D}}{n_{D}+n_{T}}=\frac{1}{2}-\frac{1}{2}\left(1-F_{1}\right)^{1 / 2}
$$

Since minimizing the hydrogenic influx can dramatically increase the plasma performance 4,5 it is clearly important to identify its dependence on plasma parameters. A dedicated experimental investigation of the parametric dependence of $F_{1}$ on plasma parameters would have required prohibitively high tritium usage, and so a study was undertaken of discharges in the existing database.

\section{Deuterium influx to the core in tritium beam fueled discharges.}

A database was constructed containing 36 plasma parameters for discharges throughout the D-T campaign. To allow time for the neutral beam heated plasma and limiter to equilibrate, the plasma parameters were averaged over the time interval $0.3-0.1 \mathrm{~s}$ before the end of beam injection (typically $1 \mathrm{~s}$ duration). Additionally, the time dependence of the quantity $F_{1}$ was examined. Three examples are shown in Fig. 1. For balanced D- and T-NBI, the measured neutron rate is similar to that predicted by eqn. 7. For T-only NBI the measured neutron rate falls below the eqn. 7 value as expected. This shortfall is larger for plasmas of lower major radius. For the more comprehensive database, discharges with the following conditions were selected: neutral beam power $>10 \mathrm{MW}$, beam duration $>0.55$ seconds, and DT neutron rate $>1 \times 10^{17} \mathrm{~s}^{-1}$. Discharges with a strong variation of $F_{1}$ with time were excluded. Discharges from a campaign to study L-mode plasmas with high recycling of both deuterium and tritium from the wall were also excluded. Nearly all the discharges were at one of three major radii $(\mathrm{R}=2.45,2.52,2.62 \mathrm{~m})$. To better reveal groupings with major radius the few discharges at other radii were not included. To calculate the plasma stored energy from magnetic measurements an interpolation of the internal inductance is necessary. ${ }^{19}$ This interpolation technique is less accurate in plasmas where the current is changed during the NBI pulse. The measurement of the perpendicular component of the diamagnetic stored energy, $W_{\text {perp }}$, does not depend on this interpolation. $W_{\text {perp }}$ is typically $2 / 3$ of the total stored energy (except early in the neutral beam power heating pulse). Discharges that deviated from the $W_{p e r p} / W_{t o t}=2 / 3$ relation by more than $20 \%$ were excluded from the plots. 

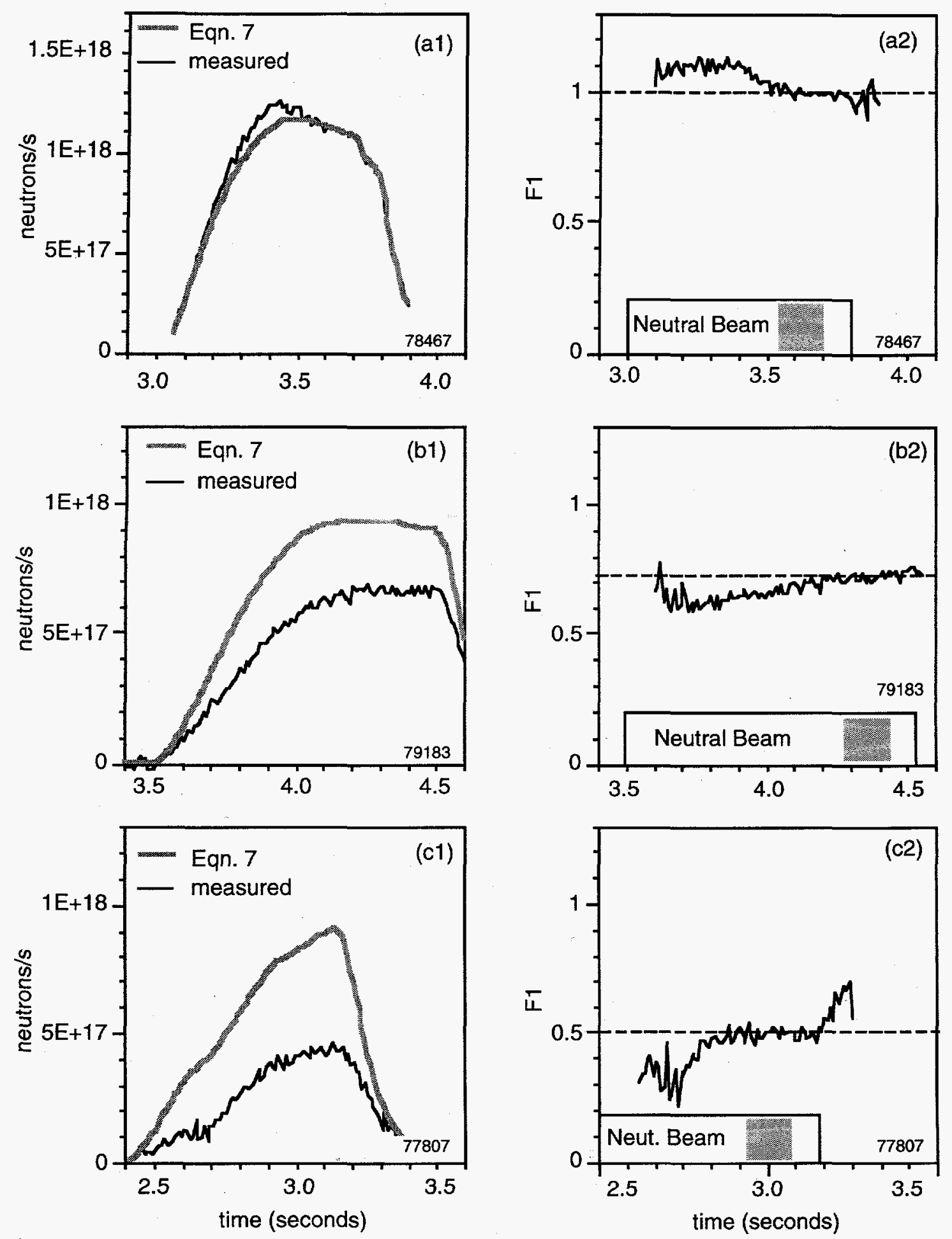

Figure 1. The time dependence of the measured DT neutron rate and that predicted by eqn. 5 in the column on the left; and the ratio between them, $F_{1}$, (see eq. 6) on the right for three types of discharges: (a) $2.52 \mathrm{~m}$ major radius plasma fueled by both $\mathrm{D}$ and T NBI; (b) $2.52 \mathrm{~m}$ major radius plasma fueled by T-only NBI; (c) $2.45 \mathrm{~m}$ major radius plasma fueled by T-only NBI. The shading and dotted line in the right hand column marks the time interval and value used in the plots below. 

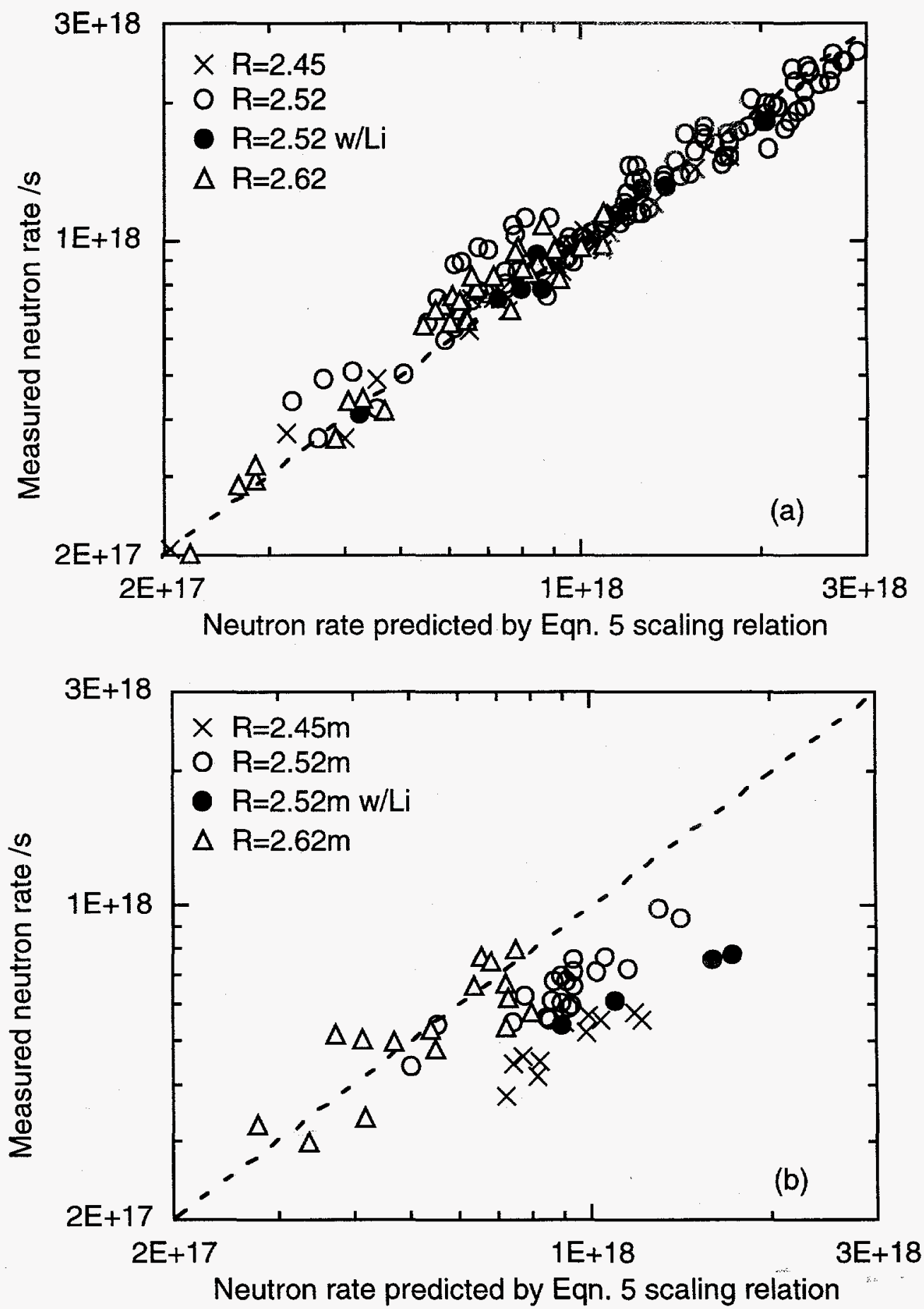

Figure 2. The correlation between the measured neutron rate and that predicted by the eqn. 5 scaling relation for (a) discharges heated by balanced deuterium and tritium NBI (b) discharges heated by tritium-only NBI. The points have intensive lithium conditioning. The deviation from the scaling relation in 2(b) is due to the reduced core deuterium fraction. A grouping with major radius or lithium conditioning is apparent in $2(\mathrm{~b})$. 
Using these criteria, a dataset of 168 discharges with a tritium fraction $35 \%-85 \%$ of the total neutral beam power was selected as a reference set. A second dataset of 51 discharges using the same criteria but tritium-only NBI was also assembled. The time of interest in the present study is near the end of the NBI phase while the regression coefficients in eqn. 5 were derived using data at the time of peak stored energy. The reference DT dataset was used to check whether eqn. 5 also applied near the end of the NBI phase. As can be seen in Fig 2 (a) the reference dataset follows the scaling relation. In particular, there is no significant grouping of plasmas with major radius.

Remarkably, as seen in Fig. 2(b), some discharges with T-only NBI showed a neutron rate lying very close to the scaling relation of eqn. 2 , indicating the mix of DT in the plasma core was close to that of discharges with balanced DT-NBI, even though beam injection was solely tritium. The lowest $S_{D T}$ was still within a factor of 3 of the scaling relation indicating that deuterium influx from the limiter is always a significant fueling source for the core plasma. An interesting difference between Fig. 2(a) and Fig. 2(b) is in the dependence on major radius. The tritium-only NBI points show a conspicuous grouping with major radius, discharges at lower major radius showing fewer DT neutrons. Another conspicuous correlation is that the tritium-only NBI discharges with intensive lithium conditioning also show a comparatively low DT neutron rate. In both of these cases we infer a lower influx of deuterium to the core.

As a further statistical check, the mean and standard deviation of the value of $F_{1}$ were calculated for the DT and T-only points at different major radii. The differences between the DT points of different major radii were within the standard deviation, while the differences between the T-only points of different major radii were outside the standard deviation and hence likely to be significant. This calculation was repeated with the datasets restricted to points where the plasma current was changed during NBI. This set warranted special attention because of the interpolation issue. The only available T-only points at $\mathrm{R}=2.45 \mathrm{~m}$ required such an interpolation. However there was no significant dependence of $F_{1}$ on major radius of the DT points in this more restricted dataset and we conclude that the effect at $\mathrm{R}=2.45 \mathrm{~m}$ is unlikely to be attributable to this interpolation.

An alternative scaling expression that has successfully matched neutron rates on several machines is given in reference 2 . This expression relates the neutron rate to the neutral beam power, $P_{B}$, and beam fueling profile peakedness, $H_{n e}$ :

$$
S_{D T}=1.95 \times 10^{16} P_{B}^{2.2} H_{n e}^{1.3} V_{p}^{-1} .
$$

$H_{n e}$ is a function of the magnitude and peakedness of the electron density:

$$
H_{n e}=2.41 F_{n e} \exp \left(-0.24 \times 10^{-19} \overline{n_{e}}\right)
$$



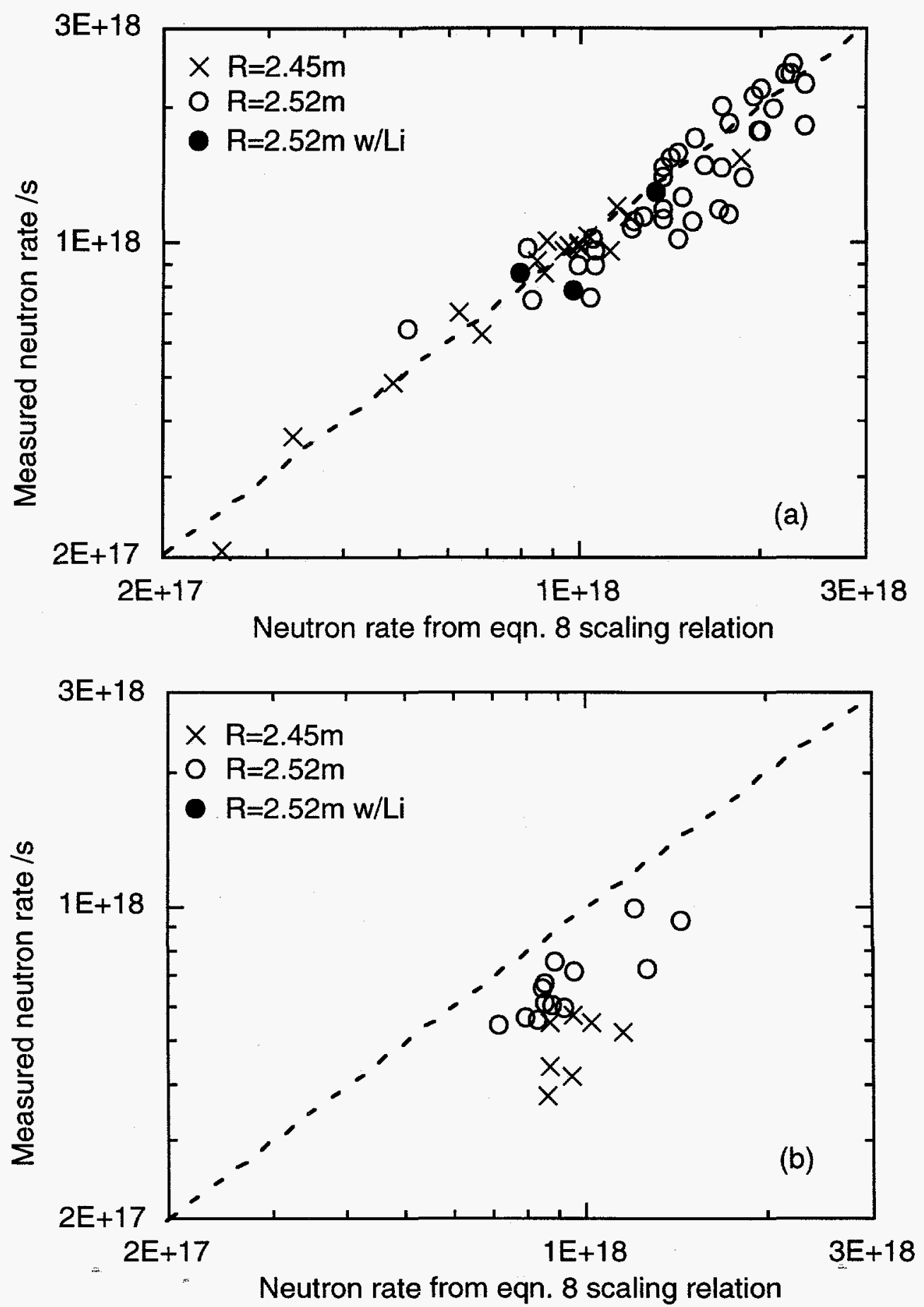

Figure 3. The correlation between the measured neutron rate and that predicted by the eqn. 8 scaling relation for (a) DT and (b) T-only NBI discharges. The deviation from the scaling relation in 3(b) is due to the reduced core deuterium fraction. The points have intensive lithium conditioning. In Fig. 3(b) a grouping with major radius is apparent, similar to Fig. 2(b). In tritium-only NBI lithium conditioned discharges, $F_{2}$ was much lower than 1 but the neutron rate increased continuously and $F_{2}$ did not reach a clear steady state condition. These points are not included in plot (b). 
where $F_{n e}$ is the peakedness of the electron density profile, $n_{e}(0) /\left\langle n_{e}\right\rangle$, and $\bar{n}_{e}\left(\mathrm{~m}^{-3}\right)$, the line average electron density. Following the previous methodology we define a ratio $F_{2}$ as:

$$
F_{2}=S_{D T} / 1.95 \times 10^{16} P_{B}^{2.2} H_{n e}^{1.3} V_{p}^{-1}
$$

This is a steady state relation, originally derived for the time of maximum stored energy, that avoids the issue of the interpolation of the internal inductance in the estimation of the stored energy in discharges with current ramps. Here we are interested in a time at the end of neutral beam injection ( -300 to -100 msec before NBI turn off). The time dependence of $F_{2}$ was examined for each discharge and only those with a steady value of $F_{2}$ for 200-300 ms near the end of the NBI phase were included. Discharges with a step down in the neutral beam power were excluded. Nearly all $2.6 \mathrm{~m}$ plasmas included RF heating; however, RF heating is not included in the eqn. 8 scaling relation. For this reason $2.6 \mathrm{~m}$ plasmas are not included in this part of the analysis. In Fig. 3 a plot of DT discharges with a tritium beam fraction between 0.35 and 0.85 showed the data following the relation of eqn. 8. There is no clear grouping with major radius. A similar plot of discharges, selected by the same criteria, but restricted to tritium-only beam injection discharges show a neutron rate that falls below the relation as expected for tritium-only beam injection, with a larger deviation for $2.45 \mathrm{~m}$ discharges.

The same dependence on major radius is apparent in both figures 2 and 3. Independent of the scaling relation used, discharges with tritium-only neutral beam injection show a DT neutron rate below that expected for discharges with balanced deuterium and tritium neutral beam injection, with a deviation that shows a clear dependence on major radius. The lower measured DT neutron rate in $2.45 \mathrm{~m}$ tritium-only discharges compared to $2.52 \mathrm{~m}$ discharges shows that the deuterium influx to the core of $2.45 \mathrm{~m}$ discharges is reduced.

The relative deuterium density, $n_{D} /\left(n_{D}+n_{T}\right)$, may be obtained from the neutron data using eqn. 7 . The relative density in the T-only NBI discharges of Fig. 2(b) is plotted against the energy confinement time in Fig. 4 (typically, improvements in the energy confinement time in TFTR have been correlated with lower influx). The points above the dashed line in Fig. 2(b) were assigned values of 0.5 (avoiding the square root of negative numbers in eqn. 7). The deuterium fraction of the central density ranges from $15 \%$ up to the mathematical limit of $50 \%$. The lowest core deuterium density occurs with $2.45 \mathrm{~m}$ major radius plasmas and those $2.52 \mathrm{~m}$ major radius plasmas that had intensive lithium conditioning. The points with intensive lithium conditioning also show the highest confinement time.

Fig. 5 shows a plot of the approximate core deuterium density vs. average hydrogenic Balmer-alpha intensity. Typically close to $2 / 3$ of the core electron density originates from $\mathrm{D}$ and $\mathrm{T}$, the remainder is from impurities and hydrogen The core deuterium density was then be derived by multiplying the 


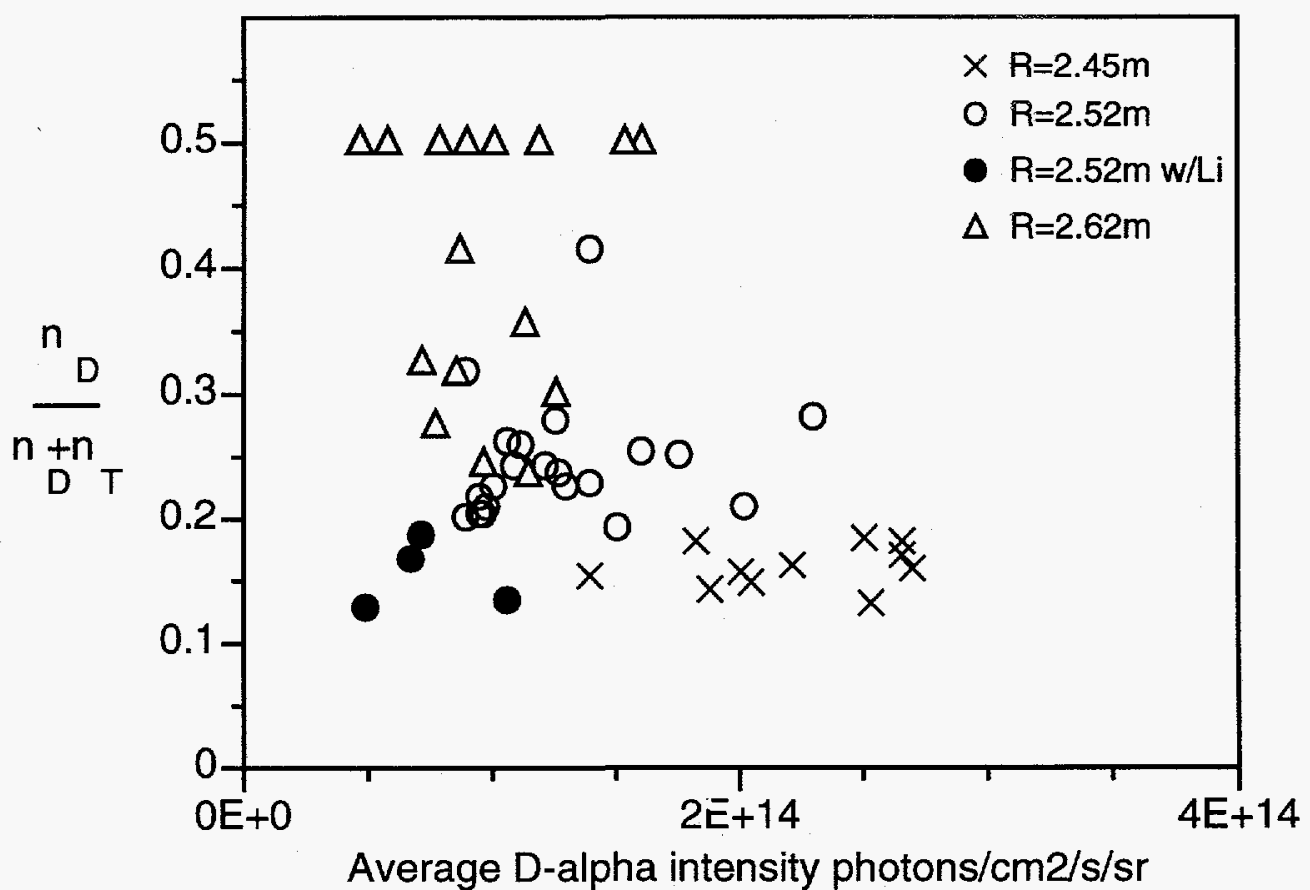

Figure 4 Points in Fig. 2(b) replotted as the core relative deuterium density vs. the energy confinement time.

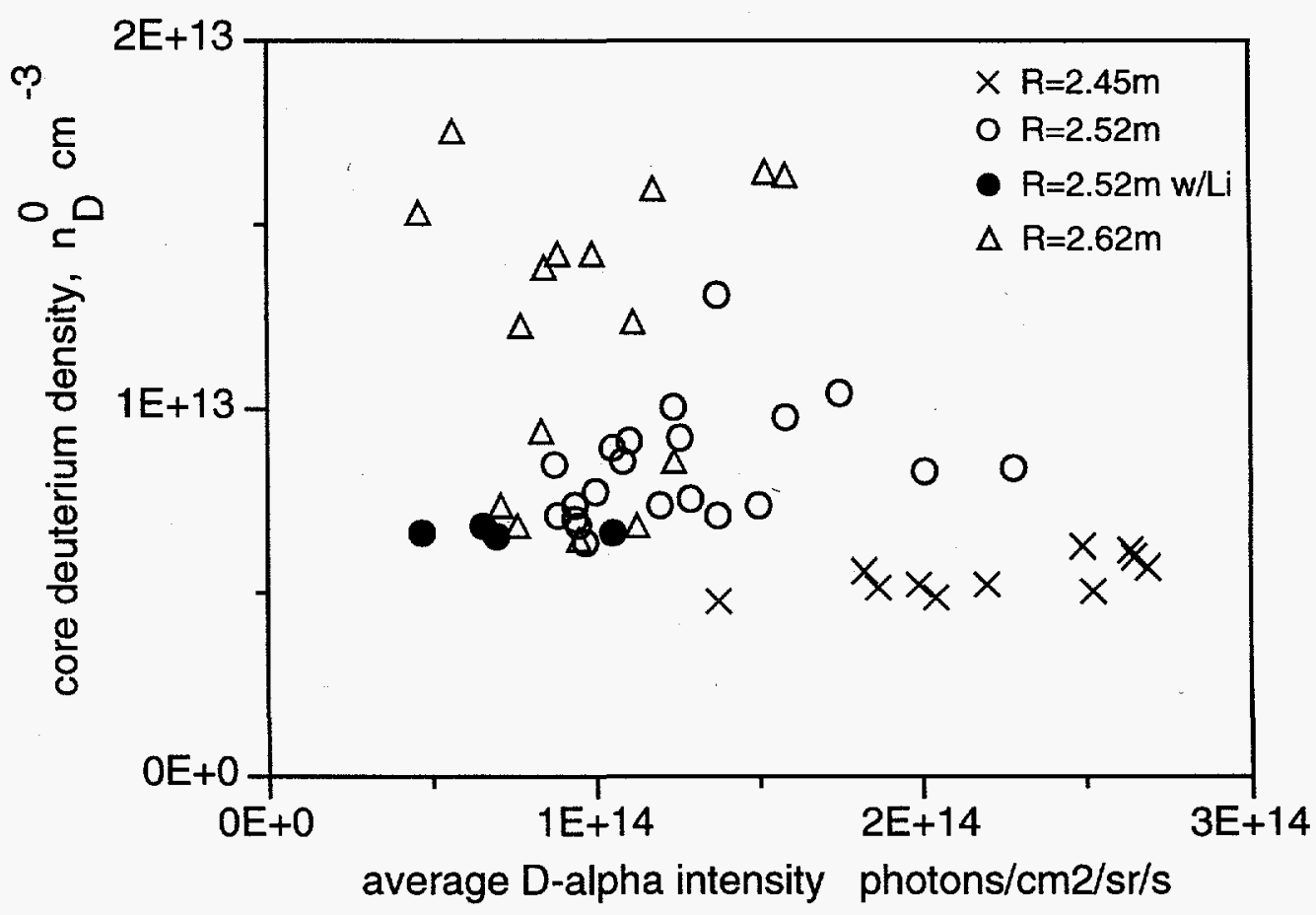

Figure 5 The derived core deuterium density, $n_{D}^{0}$ vs. the average D-alpha intensity. 
deuterium density fraction, $n_{D} /\left(n_{D}+n_{T}\right)$ by $2 / 3$ of the measured peak electron density. The Balmeralpha intensity is measured by 5 telescopes viewing $3 \mathrm{~cm}$ diameter areas at different poloidal locations on the inner limiter and wall. ${ }^{13}$ This intensity is often used as an approximate measure of the hydrogenic influx from the limiter. The neutron measurements enable one to determine the fraction of the deuterium influx that penetrates to the core plasma. The fraction of incoming neutrals that do not penetrate through the scrape-off layer is often termed the 'screening factor'. It can be seen that the $2.45 \mathrm{~m}$ major radius discharges have a high hydrogenic influx but relatively little of this influx from the limiter penetrates to the core plasma. On the contrary some $2.6 \mathrm{~m}$ plasmas have lower total hydrogenic influx from the limiter but a high probability for the influx to fuel the core. There is also a significant variation in screening factor at a given major radius. Plots of $F_{1}$ and $F_{2}$ versus plasma current, toroidal field, edge electron density, neutral beam power, energy deposited on the limiter (as measured by the product of beam power and beam duration) did not show significant correlation with major radius.

\section{Comparison with Neutral Transport Code DEGAS.}

To better understand the dependence of the deuterium influx to the core on major radius the DEGAS Monte Carlo neutral transport code 20 was used to model representative plasmas with either balanced DT or T-only neutral beam injection at major radii of $R=2.45 \mathrm{~m}, 2.52 \mathrm{~m}$ and $2.62 \mathrm{~m}$. DEGAS tracks flights of test hydrogenic neutrals from the limiter in the plasma environment of a specific discharge. A computational mesh, based on the TFTR vacuum vessel and magnetic field surfaces, is calculated by the interpretive code TRANSP ${ }^{21}$ for a specific discharge and transferred, via a post processor code, to DEGAS. Profiles for the plasma densities and temperatures within the last closed flux surface (LCFS) are also produced by TRANSP from the diagnostic measurements and are exported to DEGAS. The particle current to the limiter from the plasma scrape-off layer (i.e. outside the LCFS), is taken to scale as: $n C_{S} \sin \alpha$, where $n$ is the density, $C_{s}$ the ion sound speed and $\alpha$ is the field line angle of incidence in the poloidal plane. DEGAS is generally run under steady state conditions so that the efflux from the limiter balances the particle current to the limiter. TRANSP does not simulate the scrape-off layer. As is described in Ref. 6, the poloidal dependence of the ion current to the limiter is defined by two parameters, $\lambda$ and $\delta$. The length, $\lambda$, is the characteristic exponential decay length of the temperature and density across the scrape-off region at the outer midplane (perpendicular to the field) and $\delta$ specifies diffusion 22 perpendicular to the field lines. The values of $\lambda$ and $\delta$ are adjusted to match the predicted poloidal distribution of $D_{\alpha}$ emission to that observed. The calculated poloidal variation of the $\mathrm{D}_{\alpha}$ emission was a good fit to the observations for the $2.52 \mathrm{~m}$ cases and moderately good for the $2.45 \mathrm{~m}$ and $2.62 \mathrm{~m}$ cases. The differences are presumably due to the limitations of parameterizing a complex 3D geometry in terms of two scrape-off parameters. In DEGAS, hydrogenic neutrals are generated by dissociation, sputtering, reflection or chargeexchange. The relative $\mathrm{H}, \mathrm{D}$, and $\mathrm{T}$ neutral influxes from the limiter are adjusted to match those 
Table 1. The relative ionization of deuterium inside and outside the last closed flux surface.

\begin{tabular}{|lccccc|}
\hline major radius & $2.45 \mathrm{~m}$ & $2.45 \mathrm{~m}$ & $2.52 \mathrm{~m}$ & $2.52 \mathrm{~m}$ & $2.61 \mathrm{~m}$ \\
shot number & 86231 & 77801 & 76770 & 73447 & 74652 \\
Beam fueling & DT & T-only & DT & T-only & DT \\
$\begin{array}{l}\text { D ionization inside } \\
\text { LCFS. }\end{array}$ & $28 \%$ & $17 \%$ & $49 \%$ & $47 \%$ & $95 \%$ \\
$\begin{array}{l}\text { D ionization in } \\
\text { scrape-off }\end{array}$ & $72 \%$ & $83 \%$ & $51 \%$ & $53 \%$ & $5 \%$ \\
\hline
\end{tabular}

observed spectroscopically. The calculated spectral profile is generally in good agreement with observations. ${ }^{20}$

For the present purposes, we focus on the location of the ionization of the test particles, and sum the ionization events in two categories: inside or outside of the LCFS. Neutrals ionized in the scrape-off region outside the LCFS, flow along the field lines and tend to re-impact the limiter. Ionization in the scrape-off region tends to increase the density scrape-off length which has beneficial effects on the heat load at the limiter and impurity screening. ${ }^{23}$ Neutrals that are ionized within the LCFS can penetrate deeper into the plasma. The fraction of ionization that occurs within the LCFS reflects the core fueling efficiency of the influx from the limiter. Table 1 lists the relative ionization fraction of deuterium calculated by DEGAS. The percentage of D ionization inside the LCFS increases significantly with major radius.

In TFTR, plasmas with a lower major radius necessarily have a lower minor radius due to the limiter geometry, and a region between the limiter and the LCFS that, on average, is thicker. This increases the probability of neutrals being ionized before penetrating the LCFS. The decrease of the fraction of incoming neutrals that are able to penetrate the LCFS with decreasing major radius is in qualitative agreement with the experimental observation (sect. III) of reduced deuterium influx to the core plasma at $2.45 \mathrm{~m}$. A similar result was obtained in a study of deuterium-only neutral beam heated plasmas. 11 


\section{Summary}

Fueling of the core plasma by deuterium recycled from the TFTR limiter has been gauged by measurements of the D-T neutron rate in plasmas heated by tritium-only neutral beams. Deuterium originating from the limiter reacts with tritium injected by the neutral beams and the relative core deuterium density was derived from a comparison of the measured DT neutron rate with that expected for a balanced DT beam fueled discharge. In contrast to the traditional measure of influx based on the intensity of the Balmer-alpha emission, this method is only sensitive to deuterium that penetrates to the core plasma. The analysis shows that influx from the limiter can contribute a large fraction of the core density, in some cases up to the maximum that can be inferred - 50\%. The lowest fractions, $10-20 \%$, were found for discharges with smaller major radius $(\mathrm{R}=2.45 \mathrm{~m})$ and also for larger major radius discharges $(\mathrm{R}=2.52 \mathrm{~m}$ ) that had extensive lithium conditioning. Modeling with the neutral code DEGAS has related the reduced deuterium core influx to the reduced probability of incoming neutral deuterium penetrating the thicker scrape-off layer in plasmas of small major radius.

\section{Acknowledgments.}

The performance of the deuterium-tritium experiments on TFTR has only been possible through the dedicated efforts by all the staff at Princeton Plasma Physics Laboratory and by participants from national and international laboratories, universities and industry. Special thanks are due to $\mathrm{C} B$ Bush and $\mathrm{D}$ Mansfield for experimental campaigns at $\mathrm{R}=2.45 \mathrm{~m}$ and with lithium conditioning. This work was supported by the US Department of Energy Contract No. DE-AC02-76CH03073.

\section{References.}

1 D H McNeil, J. Nucl. Mater., 162-164, 476 (1989).

2 K M McGuire, H Adler, P Alling, C Ancher, H Anderson, J L Anderson, J W Anderson, V Arunasalam, G Ascione, D Ashcroft, C W Barned, G Barnes, S Batha, G Bateman, M Beer, M G Bell, R Bell, M Bitter, W Blanchard, N L Bretz, C Brunkhorst, R Budny, C E Bush, R Camp, M Caorlin, H Carnevale, S Cauffmann, Z Chang, C S Chang, C Z Cheng, J Chrysanowski, J Collins, G Coward, M Cropper, D S Darrow, R Daugert, J DeLooper, R Denny, W Dorland, L Dudek, H Duong, R Durst, P C Efthimion, D Ernst, $\mathrm{H}$ Evenson, N Fisch, R Fischer, R J Fonck, E Fred, E Fredrickson, N Fromm, G Y Fu, T Fujita, H P Furth, V Garzotto, C Gentile, J Gilbert, J Giola, N Gorelenkov, B Grek, L R Grisham, G Mammett, G R Hanson, R J Hawryluk, W Heidbrink, H W Herrmann, K W Hill, J Hosea, H Hsuan, M Highes, R Hulse, A Janos, D L Jassby, F C Jobes, D W Johnson, M Kalish, J Kamperschroer, J Kesner, H Kugel, G Labik, N T Lam, P H LaMarche, E Lawson, B LeBlanc, J Levine, F M Levinton, D Loesser, D Long, M J Loughlin, J Machuzak, 
R Majeski, D K Mansfield, E S Marmar, R Marsala, A Martin, E Mazzucato, M Mauel. M P McCarthy, J McChesney, B McCormack, D C McCune, G McKee. D M Meade, S S Medley, D R Mikkelsen, S V Mirnov, D Mueller, M Murakami, J A Murphy, A Nagy, G A Navratil, R Nazakian, R Newman, M Norris, T O’Connor, M Oldaker, J Ongena, M Osakabe, D K Owens, H Park, W Park, P Parks, S F Paul, G Pearson, E Perry, R Persing, M Petrov, C K Phillips, M Philips, S Pitcher, R Pysher, A L Qualls, S Raftopoulos, S Ramakrishnan, A Ramsey, D A Rasmussen, M H Redi, G Renda, G Rewoldt, D Roberts, J Rodgers, R Rossmassler, A L Roquemore, E Ruskov, S A Sabbagh, M Sasao, G Schilling, J Schivell, G L Schmidt, R Scillia, S D Scott, I Semenov, T Senko, S Sesnic, R Sissingh, C H Skinner, J Snipes, J Stencel, J Stevens, T Stevenson, B C Stratton, J D Strachan, W Stodiek, J Swanson, E Synakowski, H Takashi, W Tang, G Taylor, J Terry, M E Thompson, W Tighe, J R Timberlake, K Tobita, H H Towner, M Tuszewski, A von Halle, C Vannoy, M Viola, S von Goeler, D Voorhees, R T Walters, R Wester, R White, R Weiland, J B Wilgen, M WIlliams, J R Wilson, J Winston, K Wright, K L Wong, P Woskov, G A Wurden, M Yamada, S Yoshikawa, K M Young, M C Zarnstorff, V Zavereev, and S J Zweben, Phys. Plasmas, 2, 2176 (1995).

3 H K Park, M G Bell, W M Tang, G Taylor, M Yamada, R V Budny, D C McCune, R M Wieland, Nucl. Fusion, 34, 1271 (1994); H.K. Park, S.A. Sabbagh, S. Batha, M. Bell, R.V. Budny, C. Bush, Z. Chang, D. Johnson, D.K. Mansfield, D. McCune, K.M. McGuire, R. Nazikian, C. Skinner, R. Wieland, M. Yamada, and K.M. Young, Phys. Plasmas, 4, 1699 (1997).

4 J D Strachan, M Bell, A Janos, S Kaye, S Kilpatrick, D Manos, D Mansfield, D Mueller, K Owens, C S Pitcher, J Snipes, J Timberlake, J . Nucl. Mater. 196-198, 28 (1992).

5 D K Mansfield, K W Hill, J D Strachan M G Bell, S D Scott, R Budny, E S Marmar, J A Snipes, J L Terry, S Batha, R E Bell, M Bitter, C E Bush, Z Chang, D S Darrow, D Ernst, E Fredrickson, B Grek, H W Herrmann, A Janos, D L Jassby, F C Jobes, D W Johnson, L C Johnson, F M Levinton, D R Mikkelser, D Mueller, D K Owens, H Park, A T Ramsey, A L Roquemore, C H Skinner, T Stevenson, B C Stratton, E Synakowski, G Taylor, A von Halle, S von Goeler, K L Wong, S J Zweben, Phys. Plasmas, 3, 1892 (1996).

6 R V Budny and the TFTR group, J. Nucl. Mater. 176-177, 427 (1990).

7 R V Budny, M G Bell, D K Mansfield J D Strachan, S Zweben, H Adler, C E Bush, Z Chang, D Ernst, E Fredrickson, B Grek, L R Grisham, R J Hawryluk, D L Jassby, L C Johnson, D C McCune, M Murakami, H Park, A T Ramsey, J Schivell, S D Scott, C H Skinner, E Synakowski, G Taylor, and M C Zarnstorff, 1994 Europhysics conference abstracts Vol. 18B, (1), 82, European Physical Society.

8 S D Scott D R Ernst, M Murakami H Adler, M G Bell, R V Budny, C E Bush, Z Chang, H Duong, L R Grisham, E D Fredrickson, B Grek, R J Hawryluk, K W Hill, J Hosea, D L Jassby, D W Johnson, L C Johnson, M J Loughlin, D K Mansfield, K M McGuire, D M Meade, D M Mikkelsen, J Murphy, H K Park, A T Ramsey, J Shivell, C H Skinner, J D Strachan, E J 
Synakowski, G Taylor, M E Thompson, R Weiland, and M C Zarnstorff, Physica Scripta, 51, 394 (1996).

9 J Strachan, personal communication (1997).

10 S E Kruger, R V Budny, J D Callan, Z Chang, C H Skinner and J D Strachan, Nucl. Fusion 36, 1053 (1996).

11 R V Budny, M Bitter, H Duong, Q Gao, D Jassby, L C Johnson, S von Goeler, A T Ramsey, C H Skinner and D P Stotler, to be submitted to Phys. Plasmas. (1997).

12 L R Grisham, S D Scott, R J Goldston, M G Bell, R Bell, N L Bretz, C E Bush, B Grek, G H Hammett, K Hill, F Jobes, D Johnson, S Kaye, D Mansfield, D Mueller, H K Park, A Ramsey, J Shivell, B Stratton, E J Synakowski, G Taylor and H H Towner. Phys. Rev. Lett., 67, 66 (1991).

13 A T Ramsey and S L Turner, Rev. Sci. Instrum., 58, 1211 (1987).

14 C H Skinner, H Adler, R V Budny, J Kampenschroer, L C Johnson, A T Ramsey, D P Stotler, Nucl. Fus. 35, 143 (1995).

15 C H Skinner, J Kamperschroer, D Mueller, A Nagy and D P Stotler, J. Nucl. Mater. 241-243, 887, (1997).

16 R V Budny, Nucl. Fus. 34, 1247 (1994).

17 H H Towner, R J Goldston, G W Hammett, J A Murphy, C K Phillips, S D Scott, M C Zarnstorff and D Smithe, Rev. Sci. Instrum., 63, 4753 (1992).

18 M G Bell, C W Barnes, R V Budny, L R Grisham, R J Hawryluk, D L Jassby, L C Johnson, D R Mikkelsen, C H Skinner, J D Strachan, H Adler, P Alling, J L Anderson, G Barnes, S Batha, G Bateman, M Beer, R Bell, M Bitter, W Blanchard, N Bretz, C Bush, R Camp, M Caorlin, Z Chang, C Z Cheng, J Collins, M Cropper, D Darrow, W Dorland, H Duong, R Durst, P Efthimion, D Ernst, N Fisch, R Fischer, R Fonck, E Fredrickson, G Y Fu, T Fujita, H Furth, C Gentile, N Gorelenkov, B Grek, G Hammett, W Heidbrink, H Herrmann, K HIll, J Hosea, M Hughes, A Janos, F Jobes, D Johnson, K Kamperschroer, K Kesner, S Kruger, H Kugel, P LaMarche, B LeBlanc, F Levinton, M Loughlin, J Maaachuzak, R Majeski, D Mansfield, E Marmar, E Mazzucato, M Mauel, J McChesney, B McCormack, D M McCune, K McGuire, G McKee, D Meade, S Medley, S Mirnov, D Mueller, M Murakami, J Murphy, A Nagy, G Navratil, $\mathrm{R}$ azikian, $\mathrm{R}$ Newman, $\mathrm{T}$ O'Connor, M Oldaker, J Ongena, M Osakabe, D K Owens, H Park, S Paul, G Pearson, M Petrov, C Phillips, M Phillips, S Pitcher, A Ramsey, M Redi, D Roberts, J Rodgers, R Rossmassler, A Roquemore, E Ruskov, S Sabbagh, M Sasao, G Shilling, J Shivell, G Schmidt, S Scott, I Semenov, S Sesnic, R Sissingh, J Stevens, T Stevenson, B Stratton, W Stodiek, E Synakowski, H Takahashi, G Taylor, J Terry, M Thompson, W Tighe, J Timberlake, K Tobita, $\mathrm{H}$ Towner, A von Halle, C Vannoy, M Viola, $S$ von Goeler, D Voorhees, $R$ Weiland, $M$ Williams, J R Wilson, K L Wong, P Woskov, G Wurden, M Yamada, K Young, M Zarnstorff, V Zavereev, and $S$ Zweben. Proceedings of the 15th International Atomic Energy Agency 
Conference on Plasma Physics and Controlled Nuclear Fusion Research 1994 (September 1994, Seville Spain) IAEA Vienna, 1, 171, 1995.

19 M G Bell, V Arunasalam, M Bitter, W R Blanchard, F Boody, N Bretz, R Budny, C E Bush, J D Callen, J L Cecchi, S Cohen, R J Colchin, S K Combs, J Coonrod, S L Davis, D Dimock, H F Dylla, P C Efthimion, A C England, H P Eubank, R Fonck, E Fredrickson, L R Grisham, , R J Goldston, B Grek, R J Hawryluk, W Heidbrink, H Hendel, K W Hill, E Hinnov, S Hiroe, R Hulse, H Hsuan, D Johnson, L C Johnson, R Kaita, R Kamperschroer, S M Kaye, S Kilpatrick, H Kugel, P H LaMarche, R Little, D M Manos, D Mansfield, M McCarthy, R T McCann, D C McCune, K McGuire, D M Meade, S S Medley, S L Milora, D R Mikkelsen, W Morris, D Mueller, E Neischmidt, D K Owens, V K Pare, H Park, B Prichard, A Ramsey, M H Redi, A L Roquemore, N R Sauthoff, J Shivell, G L Schmidt, S D Scott, S Sesnic, M Shimada, J E Simpkins, J Sinnis, F Stauffer, B Stratton, G D Tait, G Taylor, H H Towner, M Ulrickson, S von Goeler, R Weiland, J B Wilgen, M Williams, K L Wong, S Yoshikawa, K M Young, M C Zarnstorff, S Zweben, Plasma Physics and Controlled Fusion, 28, 1329 (1986).

20 D P Stotler, C H Skinner, R V Budny, A T Ramsey, D N Ruzic, R B Turkot, Phys. Plasmas, 3, 4084 (1996).

21 R V Budny, Nucl. Fus. 34, 1247 (1994).

22 C S Pitcher, P C Stangeby, M G Bell, J D Elder, S J Kirkpatrick, D M Manos, S S Medley, D K Owens, A T Ramsey and M Ulrickson, J. Nucl. Mater., 196-198, 241 (1992).

23 P C Stangeby and G M McCracken Nucl. Fusion 30, 1225 (1990). 


\section{External Distribution in Addition to UC-420}

Professor Joao Canalle, Instituto de Fisica DEQ/IF - UERJ, Brazil

Mr. Gerson O. Ludwig, Instituto Nacional de Pesquisas, Brazil

Dr. P.H. Sakanaka, Instituto Fisica, Brazil

Library, R61, Rutherford Appleton Laboratory, England

The Librarian, Culham Laboratory, England

Professor M.N. Bussac, Ecole Polytechnique, France

Dr. F. Moser, Bibliothek, Institute für Plasmaforschung der Universitüt Stuttgart, Germany Jolan Moldvai, Reports Library, MTA KFKI-ATKI, Hungary

Ms. Clelia De Palo, Associazione EURATOM-ENEA, Italy

Dr. G. Grosso, Instituto di Fisica del Plasma, Italy

Librarian, Naka Fusion Research Establishment, JAERI, Japan

Library, Plasma Physics Laboratory, Kyoto University, Japan

Dr. O. Mitarai, Kyushu Tokai University, Japan

Library, Academia Sinica, Institute of Plasma Physics, People's Republic of China

Shih-Tung Tsai, Insitute of Physics, Chinese Academy of Sciences, People's Republic of China

Dr. S. Mirnov, Triniti, Troitsk, Russian Federation, Russia

Dr. V.S. Strelkov, Kurchatov Institute, Russian Federation, Russia

Mr. Dennis Bruggink, Fusion Library, University of Wisconsin, USA

Alkesh Punjabi, Center for Fusion Research and Training, Hampton University, USA

Dr. W.M. Stacey, Fusion Research Center, Georgia Institute of Technology, USA

Mr. Paul H. Wright, Indianapolis, Indiana, USA 
The Princeton Plasma Physics Laboratory is operated by Princeton University under contract with the U.S. Department of Energy.

Information Services

Princeton Plasma Physics Laboratory

P.O. Box 451

Princeton, NJ 08543

Phone: 609-243-2750

Fax: 609-243-2751

e-mail: pppl_info@pppl.gov

Internet Address: http://www.pppl.gov 